\title{
Going beyond "highly-qualified personnel" to "value-added personnel"
}

Marc Nantel, Bradley Fox, Leanne Gelsthorpe, Roxy Hamilton, Robert Marshall, et al.

Marc Nantel, Bradley Fox, Leanne Gelsthorpe, Roxy Hamilton, Robert Marshall, Guida Williamson, "Going beyond "highly-qualified personnel" to " value-added personnel"," Proc. SPIE 9664, Ninth International Topical Meeting on Education and Training in Optics and Photonics, 966419 (24 October 2005); doi: 10.1117/12.2207544

SPIE Event: Ninth International Topical Meeting on Education and Training in Optics and Photonics, 2005, Marseille, France 
Ref ETOP009

\title{
Going beyond "Highly-Qualified Personnel" to "Value-Added Personnel"
}

\author{
Marc Nantel, Bradley Fox, Leanne Gelsthorpe, Roxy Hamilton, Robert Marshall, and \\ Guida Williamson
}

Ontario Centres of Excellence (OCE) Inc.

Toronto, Ontario, Canada

\begin{abstract}
Employers clamour for more "Highly-Qualified Personnel" (HQP) to hire, and photonics is no exception. The challenge facing all new graduates lies in what actually constitutes a Highly-Qualified Person. Yesterday, an HQP was often understood to be a graduate with a Bachelor's, Master's or Ph.D. degree. Today, industry is demanding that an HQP be either a university or college graduate with strong academic standing AND a sound business and communications skill set. In this paper, we introduce the concept of "Value-Added Personnel" (VAP), which marries both scientific and "soft-skills" aspects, and we present a new program in Ontario to produce VAPs.
\end{abstract}

\section{The concept of "Value-Added Personel"}

\section{Summary}

Helping students grow into Highly-Qualified Personnel (HQP) remains one of the key objectives for universities. The challenge facing all new graduates these days lies in what actually constitutes an HQP. In its study of March 2004, "The Economic Contribution of Canada's R\&D Intensive Enterprises 1994-2001", Barber and Crelinsten state that, "The skill set of graduates is too narrow. The commerce-averse culture inhibits them from learning management, teamwork, marketing, customer relations and other commerce-related skills so necessary to excel in an R\&D-intensive firm that competes globally". They conclude in their summary that "the key issues facing R\&D Leader firms in Canada today are the need for commerce-competent, highly-skilled graduates....". A recent Canadian Manufacturers and Exporters (CME) Report lists similar skills as those most in need of improvement, in the opinion of employers. While it is the job of universities and colleges to teach their students to be scientific and technical experts, they rarely cultivate the critical skills required for a smooth and rapid integration of the graduate as a productive and competitive member of the workplace.

As a non-profit company funded by the Government of Ontario to stimulate job creation, wealth generation and economic growth in the Province, the Ontario Centres of Excellence (OCE) has been funding research in Ontario universities for almost 20 years. In doing so, it has supported graduate students in various scientific and engineering fields concentrating on photonics, environmental sciences, information technology, energy, manufacturing and materials. In a review of the programs offered by OCE, and based on an OCE student survey conducted in 2003, it was evident that although key programs were in place to enable students to interact with industry, students felt they required a set of soft skills that would better prepare them to work with industry. On the basis of stakeholder and student demand, OCE has therefore advanced a new program of study for 
graduate students who are intent in becoming more effective, to be Value-Added Personnel (VAP).

The ultimate goal of the VAP program is to enhance the innovative capacity of firms and organizations by building the networking, presentation, management and entrepreneurial skills of students so they will be employees who:

- $\quad$ Are technically superior and therefore require less internal training;

- Possess an entrepreneurial and innovative skill set;

- Possess good project-management skills;

- Have an existing network of contacts and know how to expand it;

- Understand the market and the forces influencing it;

- Understand the business environment; and

- Understand global issues/competitiveness.

\section{Surveys of students and employers:}

With this goal in mind, we have surveyed OCE-sponsored graduate students and companies from our OCE database. The following key results of the students and employers surveys confirm the need for soft-skill training of Ontario graduates:

1) Most of the respondents were at the Master's and Ph.D. level, the target group for OCE's Advanced Graduate Toolkit and Value Added Personnel Program. $83 \%$ of the respondents agree that it is important for them to take courses to improve their professional or soft skills.

2) $80 \%$ of respondents are interested in learning more about the Advanced Graduate Toolkit as it becomes available. This confirms the demand for such a program and OCE will proceed with the launch of its new program this fall.

3) $97 \%$ of employers agree that the skill-sets OCE is targeting with the Advanced Graduate Toolkit are important for the company's competitiveness, again confirming the need for the program.

4) In the subjects of "Entrepreneurship and Market Readiness", "Management and Supervision" and "Networking and Communications", the majority of employers agree that graduates today are insufficiently trained. Much of the learning of these skills is currently obtained on the job. Companies confirm that a graduate who can "hit the ground running" with a complete set of technical and soft-skills will contribute to more competitive company.

\section{The " Advanced Graduate Toolkit" (AGT)}

Providing this additional skill set is the foundation for the Advanced Graduate Toolkit (AGT), the main component of the VAP program. In order to obtain the "Advanced Graduate Toolkit" certificate, a graduate student would have to undertake OCE activities targeted at several of these skills.

\section{Requirement of the VAP program Pilot:}

1) Taking the "Core Courses" in each categories;

2) Master's student: only the four core courses are required; Ph.D. students have to add a minimum of 2 electives;

3) Participating and present at the VAP presentation competition; 
4) Participating and present at a minimum of one other conference (post-conference report required).

Our goal is to have 60 students on average in each program. Many of the AGT components below have yet to be designed and implemented, and OCE has set aside a $\$ 300,000 /$ year budget to make this happen. The new components will be rolled out over a two-year period. The list of courses and the categories in which they are classified are the following:

- Business Development and Market Knowledge

- Core course

- Intellectual Property Workshop

- Commercialization Workshop

- Marketing and Sales

- National and international Knowledge Transfer Program

- Business and Entrepreneurship

o Core course

- Business Planning Workshop

- Strategic Planning Workshop

- Business Etiquette Workshop

- Ethics Workshop

- Management and Teamwork

- Core course: Team-based OCE Project Management course

- Management/Supervision Workshop

- Leadership Workshop

- Negotiation Skills

- Networking and Communications

o Core course: Communications/Presentation Skills Workshop

- Career Management Workshop

- Emotional Intelligence

- Non-AGT elements supporting the AGT:

- Presentation competition (OCE event, Winter)

- Annual OCE-wide Student Presentation Event (Winter)

- Student newsletter

- Resume posting on OCE website

- Alumni-tracking Database

We intend to offer the VAP program to the OCE-funded students only at first, and to extend it later on to any graduate student in Ontario (and beyond).

The feedback from our stakeholders - students and industry - has been very useful to us for setting the agenda of the Advanced Graduate Toolkit and the Value Added Personnel Program. In particular, we added courses in Ethics, Business Etiquette and Emotional Intelligence as a result of survey contributions. We are currently in the process of requesting proposals from curriculum developers and training suppliers to fill our ambitious line-up of courses. While we expect to launch this program officially in the Fall 2005. 
Acknowledgements

The authors are indebted to Agnes Madej for her work on the surveys, to Tania Massa who provide a student's voice to their deliberations, and would like to acknowledge funding from the Ontario Centres for Excellence Inc.

\section{References}

1) H. Douglas Barber and Jeffrey Crelinsten, The Economic Contribution of Canada's $R \& D$ Intensive Enterprises 1994-2001, Research Infosource Inc (2004). 